\title{
Media Sosial Dalam Pembentukan Personal Branding (Studi Pada Instagram Alberta Claudia)
}

\author{
Vanesha Angelika dan Yugih Setyanto \\ Vaneshaa.ik@stu.untar.ac.id,yugihs@fikom.untar.ac.id \\ Fakultas Ilmu Komunikasi Universitas Tarumanagara
}

\begin{abstract}
This research is entitled Social Media in the Formation of Personal Branding (Study on Instagram Accounts of Alberta Claudia). The purpose of this study is to find out how social media in the formation of personal branding. This study uses qualitative research methods with a case study approach. The study used the interview method with 2 speakers who were Alberta Claudia's Instagram followers. The research data obtained is sourced from interviews and literature studies. The theory used in research is the concept offorming personal branding according to Montoya. Montoya concludes that there are several concepts of personal branding, namely specialization, personality, differences, and looks. The conclusion of this study is the personal branding formed by Alberta Claudia in accordance with the concept of forming personal branding according to Montoya.
\end{abstract}

Keywords: social media, Instagram, personal branding

\begin{abstract}
Abstrak
Penelitian ini berjudul Media Sosial dalam Pembentukan Personal Branding (Studi pada Akun Instagram Alberta Claudia). Tujuan penelitian ini adalah untuk mengetahui bagaimana media sosial dalam pembentukan personal branding. Penelitian ini menggunakan metode penelitian kualitatif dengan pendekatan studi kasus. Penelitian menggunakan metode wawancara dengan 2 narasumber yang merupakan follower instagram Alberta Claudia. Data penelitian yang diperoleh bersumber dari wawancara dan juga studi pustaka. Teori yang digunakan dalam penelitian adalah konsep pembentukan personal branding menurut Montoya. Montoya menyimpulkan ada beberapa konsep pembentukan personal branding yaitu spesialisasi, kepribadian, perbedaan, dan terlihat.Kesimpulan dari penelitian ini adalah personal branding yang dibentuk oleh Alberta Claudia sesuai dengan konsep pembentukan personal branding menurut Montoya.
\end{abstract}

Kata kunci : media sosial, instagram, personal branding

\section{Pendahuluan}

Seiring berkembangnya jaman, informasi dari berbagai belahan dunia manapun dapat diakses dengan mudah, terutama di era globalisasi saat ini yang sudah dampak dari kemajuan teknologi di dalam kehidupan manusia. Instagram merupakan salah satu media sosial yang sedang digemari oleh masyarakat indonesia. Munculnya instagram melahirkan influencer-influencer baru yang berusaha untuk dikenali oleh masyarakat. 
Menjadi influencer pastinya membutuhkan personal branding yang baik dimata masyarakat. Oleh karena itu peneliti membahas mengenai personal branding yang dibentuk oleh dr. Alberta Claudia di instagram. Personal branding yang dibentuk oleh dr. Alberta Claudia membutuhkan komunikasi yang baik dan benar.

Menurut Ruben dan Stewart dalam Alo Liliweri (2011:35) komunikasi merupakan sesuatu yang sangat esensial bagi individu, relasi, kelompok, organisasi, dan masyarakat, dia merupakan garis yang menghubungkan manusia dengan dunia. Karena itu jika manusia tidak berkomunikasi maka dia tidak dapat menciptakan dan memelihara relasi dengan sesama dalam kelompok, organisasi dan masyarakat.

Dalam melakukan komunikasi dapat dipastikan melibatkan beberapa unsur penting di dalamnya. Unsur-unsur tersebut antara lain:

a. Pengirim / sumber adalah orang yang membuat pesan.

b. Penerima adalah orang yang menafsirkan pesan yang diucapkan atau yang ditulis.

c. Encoding dan Decoding

Encoding adalah proses di mana pengirim menerjemahkan ide atau maksudnya ke dalam simbol-simbol berupa kata-kata maupun nonverbal.

Decoding adalah penerjemahan simbol-simbol verbal dan nonverbal ke dalam pesan yang bisa saja mirip, persis sama dengan, atau sangat berbeda dari apa yang dimaksudkan oleh pengirim.

d. Pesan adalah gagasan, perasaan, atau pemikiran yang telah di-encode oleh pengirim atau simbol, tanda-tanda atau kombinasi dari semuanya dan berfungsi sebagai stimulus yang akan direspons oleh penerima.

e. Saluran komunikasi merupakan sarana untuk mengangkut atau memindahkan pesan dari pengirim kepada penerima

f. Noise adalah gangguan dalam komunikasi.

g. Feedback dikenal juga sebagai umpan balik.

h. Kerangka pengalaman adalah pengalaman pengirim dan penerima yang berbasis latar belakang sosial budaya, adat istadat, pendidikan, pengetahuan, interaksi dan relasi sosial, status social

i. Konteks adalah semua komunikasi terjadi dalam konteks. Konteks dapat bersifat fisik, budaya, psikososial, dan temporal.

Menurut Mandibergh (2012, dalam Nasrullah, 2017) media sosial adalah media yang mewadahi kerja sama di antara pengguna yang menghasilkan konten (usergenerated content).

Menurut Rohmadi (2016:2) beberapa manfaat positif media sosial sebagai berikut:

a. Mendapatkan Informasi : Banyak informasi yang dapat kita peroleh lewat media sosial, seperti informasi beasiswa, lowongan kerja, info seputar agama, politik, motivasi, maupun hal-hal yang sedang tren dan dibicarakan banyak orang.

b. Menjalin silaturahmi: Melalui media sosial, kita dapat menjalin silaturahmi meski terpisah jarak, baik dengan orang baru, teman lama, maupun teman sekarang. 
c. Membentuk komunitas: Bagi yang memiliki kesukaan/hobi yang sama, dapat membentuk perkumpulan/komunitas yang berisi orang-orang dengan kesukaan/hobi yang sama.

d. Branding: Branding dalam pengertian umum merupakan kumpulan kegiatan komunikasi yang dilakukan oleh suatu perusahaan agar brand (merek) yang ditawarkan dikenal dan memiliki nilai sendiri di benak konsumen atau calon konsumen.

e. Promosi: Adanya media sosial, memudahkan orang untuk mempromosikan produk dan jasa yang dimiliki

f. Kegiatan sosial: Melalui media sosial, memudahkan dalam menggalang bantuan untuk kegiatan sosial.

Menurut Susanto dan Wijanarko (2004) brand adalah identifikasi berupa nama atau simbol yang mempengaruhi proses pemilihan suatu produk atau jasa, yang membedakannya dengan produk pesaing serta memiliki nilai bagi para pembeli dan penjualnya. Jenis-jenis branding:

a. Product branding merupakan pembangunan sebuah produk atau merek agar dapat dikenal dan sukses memimpin pasar.

b. Corporate branding adalah upaya untuk mengembangkan sebuah reputasi korporasi atau perusahaan (baik perusahaan barang maupun jasa) secara menyeluruh, dari perusahaan itu sendiri, hingga apa yang diproduksi dan ditawarkan.

c. Personal branding Selain untuk produk dan perusahaan, branding dapat dilakukan terhadap diri sendiri. Branding jenis ini disebut personal branding .

Menurut Tom Peter dalam Rampersad (2008) dasar dari konsep personal branding adalah bahwa setiap orang memiliki potensi untuk membangun merek mereka sendiri dan tugas utama dari diri mereka sendiri adalah menjadi pemasar dari merek tersebut.

Menurut Haroen (2014) personal branding di bagi menjadi dua macam yaitu:

a. Asli: personal branding yang tidak dibuat-buat

b. Palsu : personal branding yang dibuat atau disengaja

Menurut Montoya dalam Haroen (2014) terdapat delapan konsep pembentukan personal branding.

a. Spesialisasi (The Law of Specialization): Ciri khas dari sebuah Personal brand yang hebat adalah ketepatan pada sebuah spesialisasi, terkonsentrasi hanya pada sebuah kekuatan, keahlian, atau pencapaian tertentu.

b. Kepemimpinan (The Law of Leadership): Sebuah Personal Brand yang dilengkapi dengan kekuasaan dan kredibilitas sehingga mampu memposisikan seseorang sebagai pemimpin yang terbentuk dari kesempurnaan seseorang.

c. Kepribadian (The Law of Personality): Sebuah Personal brand yang hebat didasari pada sosok kepribadian yang apa adanya dan hadir dengan ketidaksempurnaan. 
d. Perbedaan (The Law of Distinctiveness) : Personal brand yang efektif harus ditampilkan dengan cara yang berbeda dari yang lainnya.

e. Terlihat (The Law of Visibility) : Personal brand berarti harus dilihat secara konsisten dan terus menerus sampai personal brand seseorang dikenal.

f. Kesatuan (The Law of Unity) : Kehidupan pribadi yang berada di balik personal brand harus sejalan dengan etika moral dan sikap yang telah ditentukan dari brand tersebut.

g. Keteguhan (The Law of Persistence) : Personal brand tidak bisa terjadi secara instan, ia membutuhkan waktu untuk tumbuh.

h. Nama Baik (The Law of Goodwill) : Sebuah personal brand akan memberikan hasil yang baik dan bertahan lebih lama, jika seseorang dibelakangnya dipersepsikan dengan citra yang positif.

\section{Metode Penelitian}

Penulis menggunakan jenis penelitian kualitatif. Menurut Haris Herdiansyah (2011) penelitian kualitatif adalah suatu penelitian ilmiah yang bertujuan untuk memahami suatu fenomena dalam konteks sosial secara alamiah dengan mengedepankan proses interaksi komunikasi yang mendalam antara peneliti dengan fenomena yang diteliti. Dalam melakukan penelitian ini penulis.

Penulis mengumpulkan data dengan menggunakan teknik wawancara, observasi pada instagram dr. Alberta Claudia, dan juga studi kasus pada instagram dr. Alberta Claudia dengan para followers dr. Alberta Claudia.

\section{Hasil Temuan dan Analisis}

Menurut Mandibergh (2012, dalam Nasrullah, 2017) media sosial adalah media yang mewadahi kerja sama di antara pengguna yang menghasilkan konten (usergenerated content).

Menurut Tom Peter dalam Rampersad (2008) dasar dari konsep personal branding adalah bahwa setiap orang memiliki potensi untuk membangun merek mereka sendiri dan tugas utama dari diri mereka sendiri adalah menjadi pemasar dari merek tersebut.

Dalam penelitian ini penulis melakukan wawancara dengan dr. Alberta Claudia dan followers instagram dr. Alberta Claudia, Maulidina Dania Putri dan Delia nuranaffi.

\section{a. Media sosial dalam pembentukan personal branding}

Dari hasil wawancara peneliti dengan dr. Alberta Claudia tentang media sosial dalam pembentukan personal branding dr. Clau menjadikan kegiatan sehari-hari sebagai konten instagramnya. Konten yang dibuat oleh dr. Clau sangatlah beragam seperti konten mengenai dunia permodelan, konten mengenai kesehatan dikarenakan dr. Clau merupakan seorang dokter. dr. Clau menjadikan aktivitasnya menjadi dokter 
sebagai konten kesehatan untuk instagramnya, dalam hal ini dr. Clau sering membagi informasi maupun membuka $Q \& A$ melalui instagram story untuk berkomunikasi dengan para followernya, konten kesehatan ini dapat kita lihat melalui instagram dr. Clau di highlight dengan nama ER LYFE.

Seperti yang dikatakan oleh dr. Clau saat diwawancara oleh peneliti mengenai konten yang dibuat olehnya

"iya, di instagram aku isi kontennya campur sih, enggak ada yang monoton selalu melulu tentang kesehatan aja, aku ada campur juga dengan kegiatan aku kalo lagi shooting, terus kayak kegiatan aku kalo lagi jadi host pas isi acara kesehatan, ada juga kegiatan keseharian aku kayak kalo aku ikut seminar atau apa”

Selain membuat konten kesehatan, dr.Clau juga membuat konten fashion designer miliknya di fitur highlight instagramnya dengan nama u\&couture dan u\&couture SS2018. Dalam konten ini dr. Clau membuat konten tentang design baju yang di design oleh dr. Clau sendiri dan dijual di butik baju pesta milik mamanya. Pada highlight ini dr. Clau mempromosikan gaun pesta model terbaru.

Bukan hanya konten itu saja yang dibuat, karena dr.Clau merupakan salah satu host dalam acara kesehatan disalah satu stasiun TV Indonesia, dr. Clau juga membuat konten DR OZ yang dapat dilihat melalui highlight instagram dr.Clau dengan nama DR OZ, dalam highlight ini dr.Clau membagi informasi apa saja yang akan dibahas dalam acara dr. Oz tersebut dan kapan acara dr. Oz akan tayang, konten ini dibuat dengan tujuan agar para follower dr.Clau tidak melewatkan informasi kesehatan yang sekiranya sedang dibutuhkan. Selain membagi informasi dr. Clau juga membagikan aktivitas syuting acara dr. Oz dalam highlight instagramnya.

Menurut hasil wawancara dengan dr. Clau ada beberapa manfaat positif media sosial menurut Rohmadi yang digunakan oleh dr. Clau yang pertama adalah mendapatkan informasi, dalam hal ini dr. Clau menjadi informan atau orang yang memberikan informasi untuk followernya, baik mengenai kesehatan, dan juga mengenai fashion, karena dr. Clau tertarik untuk mengambil spesialis kardiolog jadi dr. Clau sering membagikan tentang EKG jantung pasiennya melalui instagram story. Dari hasil-hasil EKG milik pasien ini, dr. Clau menyatukannya dalam highlight ER LYFE

Menjalin silaturahmi merupakan salah satu manfaat positif dari media sosial, dr. Clau juga menjadikan salah satu manfaat positif ini untuk dapat terus menjalin silaturahmi dengan teman-teman maupun follower dr. Clau. Karena ditengah kesibukannya dr. Clau pastinya jarang memiliki waktu luang untuk bertemu dengan teman-temannya.

Selain itu menurut rohmadi manfaat positif media sosial lainnya adalah branding, hal ini merupakan hal yang dilakukan oleh dr. Clau dalam mengelola instagramnya. dr. Clau membranding diri nya atau melakukan personal branding melalui instagramnya dengan mengomunikasikan keberadaan dirinya, dan 
menawarkan apa yang ingin ditawarkan seperti membuka QnA melalui instagram story.

Promosi juga merupakan salah satu manfaat dari media sosial. Dalam hal ini dr. Clau melakukan promosi dengan mempromosikan barang-barang yang di endorskan ke dr. Clau. Tidak lupa dengan konten, dr. Clau juga membuat konten promosinya dengan nama CLAUDIARY yang dapat kita lihat di highlight instagram milik dr. Clau. Dalam highlight ini dr. Clau menyimpan semua instagram story yang isinya mempromosikan barang yang di berikan kepada dr. Clau.

Dalam hal ini peneliti menyimpulkan bahwa dr. Clau berkomunikasi menggunakan media sosial, dengan media sosial ini dr. Clau memperkenalkan personal brandingnya dengan menggunakan fitur instagram story dan highlight yang disediakan oleh instagram. Media sosial merupakan salah satu sarana yang digunakan oleh dr.Clau untuk memperkenalkan dirinya kepada masyarakat. dr. Clau membentuk personal branding di mata masyarakat dengan kepribadian seorang dokter yang bukan hanya memperdulikan tentang kesehatan saja, namun juga seorang dokter yang peduli tentang fashion dan juga seseorang yang membagikan kehidupan pribadi yang sesungguhnya kepada para followernya. Seperti yang dikatakan oleh salah satu narasumber yang diwawancara oleh penulis

"kalo aku ngeliat instagram Alberta tuh beda sama instagram influencer lain yang palingan biasanya yang di post di instagram feeds mereka tuh kayak cuman tentang liburan, shopping, dll. Tapi kalo Alberta tuh selain membagikan informasi seputar kesehatan, tapi juga membagikan informasi tentang fashion, terus kadang juga dia ada post tentang keponakan-keponakannya yang lucu-lucu, jadi aku suka aja gt liatnya gk bosen."

Seperti yang dikatakan oleh Dania sebagai narasumber penulis, hal ini membuktikan bahkan dr. Clau berhasil membentuk personal brandingnya dimata salah satu followernya.

\section{b. Pembentukan personal branding melalui instagram dr. Clau}

Menurut hasil wawancara, dr. Clau membentuk personal brandingnya dimata masyarakat untuk menjadi dirinya sendiri atau asli. Karena pada awalnya dr. Clau tidak pernah bertujuan untuk menjadi influencer seperti sekarang ini

"sebenernya pertama kali itu aku gk pernah terpikir buat jadi influencer, karena aku awalnya mulai main instagram itu cuman buat hobi dulu buat post foto-foto yang aku suka, aku sendiri berawal dari gadis sampul dulu,ketika smp dan mulai dari situ aku suka foto-foto, jadi bikin account instagram dan memang banyak foto karena aku juga pernah berprofesi jadi model jadi suka banyak fotofoto yang lebih mengarah ke fashion, nah karena emang aku sendiri lama di majalah gadis mungkin ada beberapa followers aku juga memang pembaca gadis, jadi mulai dari sana followersnya jadi lebih cepet naik, oleh karena itu karena makin banyak jadi secara tidak langsung saya menjadi influencer" 
Dari jawaban dr. Clau saat diwawancara ini menunjukan bahwa personal branding yang dibuat oleh dr. Clau adalah asli. Karena konten yang dibuat oleh dr. Clau bukan dibuat karena unsur kesengajaan untuk membuat branding untuk dirinya agar disukai oleh para masyarakat sehingga mendapatkan banyak followers.

Berdasarkan hasil wawancara dr. Clau merupakan salah satu influencer yang memiliki beberapa konsep dalam pembentukan personal branding yaitu spesialisasi, kepribadian, perbedaan, terlihat, kesatuan, dan keteguhan.. Peneliti dapat mengatakan bahwa dr. Clau memiliki spesialisasi dikarenakan seperti yang dijabarkan oleh peneliti di bab sebelumnya, dr. Clau merupakan salah satu influencer yang memiliki gelar dokter yang meraih nilai tertinggi dalam Uji Kompetensi Mahasiswa Program Profesi Dokter (UKMPPD) se-indonesia dengan nilai 90,5. Dari hal ini, peneliti menyimpulkan bahwa informasi mengenai kesehatan yang selama ini diberikan oleh dr.Clau dapat dipercaya karena dr. Clau sudah lulus dalam kuliah kedokterannya.

kita dapat melihat bagaimana cara dr. Clau menulis caption yang tidak membosankan, setelah menjelaskan setiap hari kerumah sakit bukanlah hal yang membosankan, dr. Clau memberikan imbuhan mengenai ekspektasi dan realita menjadi dokter. peneliti mendapatkan salah satu konsep pembentukan personal branding yaitu kepribadian, pada hal ini dr. Clau menunjukan sosok kepribadian yang apa adanya dan hadir dengan ketidaksempurnaan menjadi seorang dokter kepada para followernya.

Konsep personal branding lainnya yang digunakan oleh Alberta adalah terlihat, dalam hal ini pembentukan personal branding. Personal brand berarti harus dilihat secara konsisten dan terus menerus sampai personal brand seseorang dikenal. Maka visibility lebih penting dari ability. Supaya visible seseorang, seseorang perlu mempromosikan dirinya dan menggunakan setiap kesempatan untuk membuat dirinya terlihat.

Dr. Clau membuat dirinya selalu terlihat menjadi seorang dokter yang bukan hanya memperdulikan tentang kesehatan tetapi juga peduli dengan fashion dan juga kehidupan pribadinya. Hal ini dapat kita lihat dari feeds instagram milik dr. Clau yang mengupload foto-foto mengenai kegiatan kesehatan, fashion, dan juga kehidupan.

Konsep lain yang dimiliki oleh dr. Clau adalah kesatuan, pada hal ini dapat kita lihat bagaimana dr. Clau mengenalkan keluarganya melalui instagram. Seperti yang peneliti ketahui melalui hasil observasi, dr. Clau memang tumbuh di keluarga yang sudah memiliki bidang kedokteran. Ayah kandung dr. Clau, Dr. Hendrawidjaja Undarsa, sp.PD merupakan dokter Spesialis Penyakit Dalam. Ia menyelesaikan studi kedokteran di Universitas Padjadjaran. Sekarang, ia berpraktik di Siloam Hospitals Kebon Jeruk, Rumah Sakit Pertamina Jaya. (sumber : https://www.guesehat.com/albertus-hendrawidjaja-undarsa) 
Konsep personal branding yang digunakan oleh dr. Clau adalah keteguhan. Membentuk personal branding bukanlah hal yang dapat terjadi secara instan, personal branding membutuhkan waktu untuk tumbuh agar dapat membentuk persepsi masyarakat terhadap individu tersebut. Oleh karena itu sesuai dengan hasil observasi peneliti pada instagram dr. Clau, peneliti melihat adanya keteguhan yang dilakukan dr. Clau di instagramnya. Dilihat dari seberapa aktif dr. Clau membahas mengenai kesehatan dan fashion serta membahas topik yang sedang trend saat ini.

\section{Simpulan}

Berdasarkan hasil penelitian yang telah dilakukan oleh peneliti mengenai media sosial dalam pembentukan personal branding dalam instagram Alberta Claudia, maka peneliti dapat menyimpulkan sebagai berikut: Dr. Clau menggunakan media sosial sebagai sarana komunikasi untuk mengenalkan dirinya kepada masyarakat. Personal branding yang dilakukan oleh Alberta Claudia dalam instagramnya merupakan personal branding yang sesuai dengan kepribadiannya, tanpa dibuat-buat. Dalam membentuk personal branding dalam instagram, Alberta Claudia menggunakan konsep personal branding spesialisasi, kepribadian, perbedaan, dan juga terlihat.

\section{Ucapan Terima Kasih}

Penulis mengucapkan terima kasih kepada Tuhan Yang Maha Esa, dosen pembimbing Yugih Setyanto S.Sos., M.Si., keluarga, pacar, dan juga teman-teman yang turut membantu dan mendukung penulis dalam melakukan penelitian ini.

\section{Daftar Pustaka}

Haroen, Dewi. 2014. Personal Branding. Jakarta : PT Gramedia Pustaka Utama.

Herdiansyah, Haris. 2014. Metodologi Penelitian Kualitatif. Jakarta: Salemba Humanika

Liliweri, Alo 2011. Komunikasi Serba Ada Serba Makna.Jakarta : Prenada Media Group.

Nasrullah, Rulli. 2017. Media Sosial : Perspektif Komunikasi, Budaya, dan Sosioteknologi. Bandung: Remaja Rosdakarya.

Rampersad, Hubert K. 2008. Authentic Personal Branding. Jakarta: PPM Publishing.

Rohmadi, Arif. 2016. Tips Produktif Ber-Social Media. Jakarta: PT. Gramedia.

Soraya Iin.2017. Personal Branding Laudya Cynthia Bella Melalui Instagram (Studi Deskriptif Kualitatif Pada Akun Instagram @Bandungmakuta). 
Vanesha Angelika dan Yugih Setyanto: Media Sosial Dalam Pembentukan Personal Branding (Studi Pada Instagram Alberta Claudia)

Akademi Komunikasi Bina Sarana Informatika

Priyono Joko Bambang. 2014. Strategi Menciptakan, Mempertahankan dan Menjual Personal branding Jelang Pemilu 2014. LIA Mercubuana 